\title{
Threaded Connectors for Sandwich Pipes - Part 1: Parametric \& Comparative Studies
}

Ikechukwu Onyegiri, Maria Kashtalyan*

Centre for Micro- and Nanomechanics (CEMINACS), School of Engineering, University of Aberdeen, Fraser Noble Building, Aberdeen AB24 3UE

*Corresponding author: $\underline{\text { m.kashtalyan@abdn.ac.uk }}$

\begin{abstract}
A concept for using snap-fit connectors in sandwich pipes is investigated numerically in two companion papers using a combination of $2 \mathrm{D}$ axisymmetric and 3D finite element models in Abaqus.

In the Part 1 paper, results of key parametric studies related to the installation of sandwich pipes in deepwater are reported. The modification of the nib groove to include variable radii, the use of an elastomeric seal coupled with compressive pre-stress and an optimum resin-to-core ratio all proved to enhance the performance of the sandwich pipe snap-fit connectors. The influence of the interlayer adhesion configuration on the stress concentration experienced in the connector is also studied. Furthermore, a comparative study is performed to investigate the mechanical behaviour of the snap-fit connector concept in sandwich pipes and conventional pipe-in-pipe.

In the Part 2 paper, an optimisation study is carried out for the stress relief groove (SRG) in the pin of the snap-fit connector. A combined parameter is proposed to capture the relationship between the investigated geometric properties and the stress concentration factor at the SRG. It is established that the fillet radius could indeed be used to offset the drop in performance associated with increasing the SRG depth while improving the fatigue characteristics of the connector threads.
\end{abstract}

\section{Keywords}

Pipe joining, finite element modelling, snap-fit connector 


\section{Introduction}

The potential of sandwich pipes to extend pipeline installation depths is one that has been studied for over a decade. In relation to a conventional pipe-in-pipe system, sandwich pipes have been identified as a prospective option to lowering the weight requirement for deepwater installation whilst providing the required thermal conditions to ensure flow assurance (Estefen et al., 2004, Castello and Estefen, 2008, Arjomandi and Taheri, 2012, Estefen et al., 2016). The recent oil economics has pushed deep and ultra-deep water further into the red zone in relation to future investments in the both exploration and production sectors of the oil and gas industry, with main challenges being its high end cost and not fully developed procedures (Adeosun, 2016). Reducing costs in all areas of the planning and development for deepwater reserves remains a challenge facing the industry; also in a time where solutions must be technically viable and adhere to strict safety measures.

Threaded connectors have not enjoyed the same patronage as a pipeline joining method as welded joints owing to a high level of confidence and track record in offshore welded connections which many contractors see as a cost effective and technologically advanced method (True 1996). This, added to general perceptions on the performance of threaded connectors (limited pressure integrity, complex make-up procedures and machining tolerances, corrosion protection of the thread, high cost, etc.) make the general use of threaded connectors less favourable (Walters and Thethi, 2002).

In other to withstand the added hydrostatic pressure associated with deepwater installations, a large wall thickness will be required, which translates to more steel and heavier components. One solution proposed to this is improving the grade of steel used (high strength steels), which would mean a reduction in wall thickness although that comes with its own drawback in form of welding limits (Thethi and Walters, 2003). The welding of high strength steels presents a problem as hardening of the substrate is difficult to control (wettability) which could potentially lead to a grainy heat affected zone which could be a favourable spot for hydrogen induced corrosion cracking (HSEUK, 2003). This would also lower the load carrying ability of the joint and reduce its efficiency under corrosive environments. As regards the field joint region which represents a point of potential failure in a pipeline system, threaded connectors offer an alternative to joining pipelines and risers in deepwater. 


\section{Threaded and Coupled Connectors}

Typical threaded and coupled (T\&C) joints consist of right-hand/left-hand opposed threaded profile on the outer surface of the pipe ends with notches cut into the pipe ends, an internally threaded coupling and a metal seal ring that fits between the pipes end acting as a metal-to-metal seal. Threaded joints for flowlines can be broadly categorised into two depending on the make-up mechanism: torque-driven and hydraulically assisted clamped joints. Both categories have been significantly improved upon leading to better connections although for connecting tubulars such as drill pipes, torque-driven joints are exclusively used, and currently in the industry, have been generally standardized. Following recent advancements in the use of T\&C for offshore pipelines, more specialised equipment is now available for custom threading and more optimised joint geometries leading to various proprietary T\&C joints which claim to be suited for deepwater operation of pipe-in-pipe systems. In view of this, research into these joint types would be expedited by gaining full understanding into the joint setup, geometrical improvements and, its limitations. So far with recent developments, the most publicly utilized sub-categories for the hydraulically assisted clamped joints remain the push-fit and snap-fit connectors (Verbeck and Holland, 2010, Pollack and Riggs, 2011, OSI, 2013). Both sub-categories achieve the joining of pipelines by some means of radial-interference and surface friction and as such its integrity is largely dependent on surface preparation. For the push-fit joint one end is threaded (usually the box) while the pin is designed to have a slightly larger outer diameter than the inner diameter of the box. During make-up the pin is forced into the box thus deforming the threads and creating multiple metal-to-metal seals. The technology has been enhanced by the application of special set epoxies which both aid in sealing and lubrication during joining. An example is the Positive Seal Coupling by Jetair International Inc. as shown in Figure 1. The method enjoys advantages ranging from short make-up time to ease of liner adaptation (for sour service) although from a joint strength perspective, it underperforms when compared to girth welded joints and seal integrity is somewhat difficult to manage. Major design considerations include seal face length, interference depth, tangent modulus of the pipe and coefficient of friction in the joint (True, 1996). 


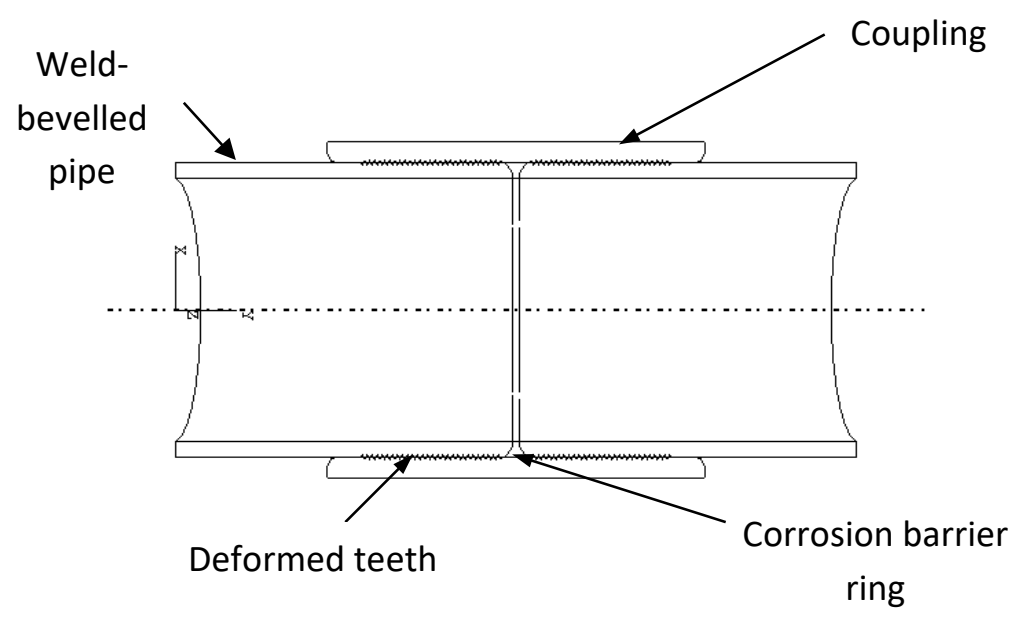

Figure 1 Typical push-fit connector

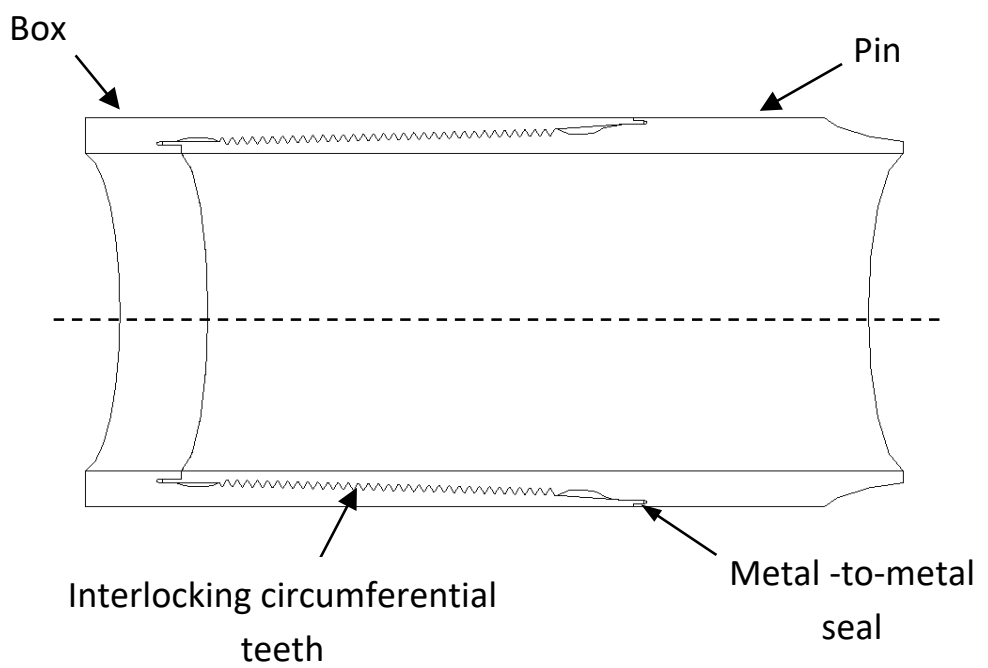

Figure 2 Typical snap-fit connector

Because of the inadequacies of the push-fit joint, snap-fit connectors were rolled out with some changes to that of the push-fit connector. Firstly, some form of geometrical interference, which involved machining, primarily ensured the joint bond. Make-up is achieved by expanding one end of the pipe (box end) and hydraulically inserting the straight end of the adjacent pipe (pin end) to achieve an interference fit. A good example can be seen in Hunting's Merlin connector where threads are machined on both pin outer surface and box inner surface to aid the interference fit (Figure 2). Many variations exist to snap-fit connectors with geometrical variations being patented and proprietary to various companies (e.g GMC Intelligently Connected Pipe). Additional grooves can be incorporated to facilitate extra seal locations in the joint and modified threaded profile can aid in reducing the stress concentrations at the thread roots (Van Wittenberghe et al., 2011). 
Threaded connectors have been utilised in offshore oil pipelines with a good track record and although the industry remains sceptic towards it in relation to welded connections, they serve economically well especially in shallow waters. Under installation loads, a conventional threaded connection will have peak stresses located at the root of the first engaged thread (FET) of the pin and last engaged thread (LET) of the box (Tafreshi, 1999). Due to the stiffness variation that usually occurs between the T\&C connectors and the parent pipe, mechanically connected pipeline installation by the reeling method is not yet technologically feasible, with the complexity increasing for large diameter pipes. Therefore when it comes to installation preference for laying T\&C connectors in deepwater, the J-Lay method would more than likely be a better choice as plastic bending of the parent pipe is not expected at the sagbend (Bai and Bai, 2005b).

It should be emphasized at this point that although T\&C connector design is properly standardised for drill pipes and to some extent for risers, when it comes to its application for oil and gas pipelines, proprietary joint types rule the market space. Some would argue that this is as a result of the uniqueness of multiphase oil and gas transport and flow conditions while some would blame it on a weightier industry confidence on welding as a preferred joining method for pipelines. This on the other hand has helped forge a new business line for joint designers who seek to develop new and modified systems to make economic profit. Now, threaded connectors for flowlines are certified by ISO 21329 (2004) and follow strict adherence to operational health and safety.

\section{Snap-fit Connectors}

This paper aims to identify the fatigue critical regions for a snap-fitted sandwich pipe and explore modifications to reduce the stress concentration in such regions. The relationship between the stress concentration at these regions and the connection's mechanical/geometrical properties are investigated for typical installation loads (bending, external pressure and axial loading). The formulation of optimization parameters to predict connection performance via parametric finite element analysis in Abaqus (Dassault Systèmes 2014) is also studied, in particular geometrical properties of the nib groove and stress relief groove. A better understanding of the added complexities to the snap-fit connector for its utilization in sandwich pipes is gained from the results from this study. As a complex multiaxial stress distribution is expected over the connection, the maximum principal stress is used.

Unlike helical threaded profiles for drill pipes, snap-fit connectors for pipelines and risers generally employ parallel interlocking teeth with joint design carried out in such a way that perfect interlock cannot be achieved until the joint is fully made-up (True 1996). Injected annulus pressure is used to 
expand the box and shrink the pin whilst an external clamping tool is used to snap the two ends.

Disconnection can be achieved by simply depressurizing the annulus and with its fast make-up, considerable cost savings can be accrued by using this type of connector (Pollack and Riggs, 2011). Multiple metal-to-metal seals can be incorporated with precise stab in points to ensure high seal integrity. Pressurized hydraulic fluid in the annulus can be used to create a preloaded condition in the joint. Snap-fit connectors are not subject to any of the uncertainty found in rotational connectors caused by torque and friction effects (True 1996). Most snap-fit connectors utilise custom joint geometries and have a higher number of threads per inch (T.P.I) than specified for their nominal pipe diameter according to ASME-B1.20.1 (2013) with the aim of achieving a more precise fit and better seal integrity. An example is the GMC's Intelligently Connected Pipe (ICP) connector shown in Figure 3a. With that in mind a clear distinction can be made between snap-fit connectors for pipelines/risers and threaded line pipes for tubulars like drill pipes. Although they share some similarities in load and stress distributions and as such knowledge from drill pipes can be extended to better understand the mechanical behaviour of snap-fit connectors for utilisation in sandwich pipes. Snap-fit connectors through the years have proven to be viable solutions for joining subsea pipelines (Craig and Dick, 1995) (Geertsen et al., 2017) and as such can be transferred for use in sandwich pipes with a few modifications.

For application in sandwich pipes, snap-fit connectors could either be welded to the inner pipe ends or machined on an upset end. This would be done at a yard onshore and would save considerable offshore time. Also, it would only require one joining station offshore. Transference of axial loads between the inner and outer pipe during installation and operation would be made possible by the installation of a loadshare, which would also help reduce residual compressive stresses in the inner pipe when laid on the seabed due to variation in bending stiffness along the sagbend. A sleeve can be adopted to bind the field joint (this would be dependent on the stress and strain concentrations around the snap-fit connector) and resin injection into the annulus of the field joint would still be a preferable way to mitigate flow assurance problems at the field joint whilst inhibiting rotation and offering protection against bending and impact loads. We would call this Option 1 and an illustration of this is shown in Figure 4a. It can be seen that other geometrical modifications have been made to address certain issues with the snap-fit joint type for sandwich pipes. As would be expected, the transition zone between the inner pipe and snap-fit connector would be an area of interest, which would depend on the relative difference in wall thickness between the pipe and the connector, the cut back length and the radii profile of the transition fillet. Designing the transition fillet with variable radii and using materials with closely matched stiffness have been identified as potential 
solutions to reducing the stress concentration and improving fatigue strength at this zone (Taylor et al., 2011).

Owing to the reduced wall thickness of the outer pipe in a sandwich pipe, the stress concentration at the inner pipe - loadshare boundary would be larger than in a case when a conventional pipe-inpipe system is used for the same installation top tension. The length of the loadshare does affect the axial load distribution and the SCF as seen in Figure 3b. The so-called "elastic SCF" is used for this study as defined by the formulation:

$$
\text { Elastic SCF }=\frac{\text { Stress }(\text { geometry of interest })}{\text { Stress }(\text { Pipe })}
$$

Another possible configuration (Option 2 ) is shown in Figure $4 \mathrm{~b}$. This utilises a swaged outer pipe welded to the connector section and a longer sleeve. The connector is machined as an upset end of the inner pipe. Preliminary analysis showed that increasing the length of the sleeve has an advantageous effect by lowering the bending stresses; the sleeve carries more bending load as the length is increased. Due to fabrication, installation and maintenance advantages, Option 2 is investigated further. From installation experience, Option 1 will suffer setbacks such as too many loadshares to design and weld, high stress regions at loadshare boundaries, more difficulty to repair and would definitely cost more to fabricate and install.
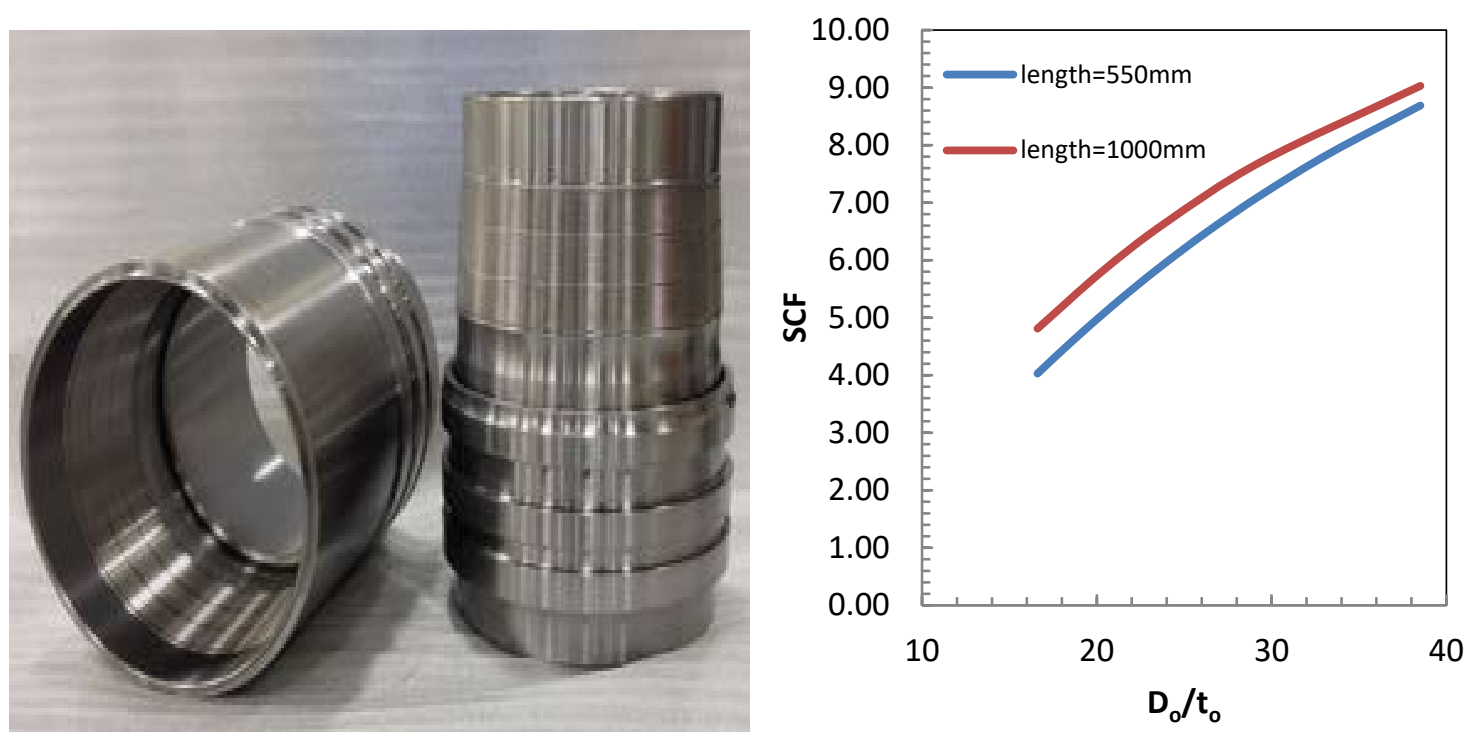

Figure 3 (a) GMC Intelligent Connector (GMC, 2014) (b) Variation of SCF around loadshare boundary with outer pipe diameter to thickness ratio $\left(D_{0} / t_{0}\right)$

\section{Nib groove}

A critical zone in the snap-fit connector is the nib groove, which acts as a redundant metal-to-metal seal. As can be seen in Figure 4a, the groove reduces the wall thickness at this region and hence 
reduces its stiffness. Coupled with the geometrical transition, stress concentrations would normally arise at the exit of the nib groove radii under axial and bending loads (Pollack and Riggs, 2011).

Elastomeric materials can be utilised in the nib groove to create a compression field during preload, which then improves the fretting resistance of the seal as long as the filler material is not stiffer than the connector material as would be seen later on in the paper.

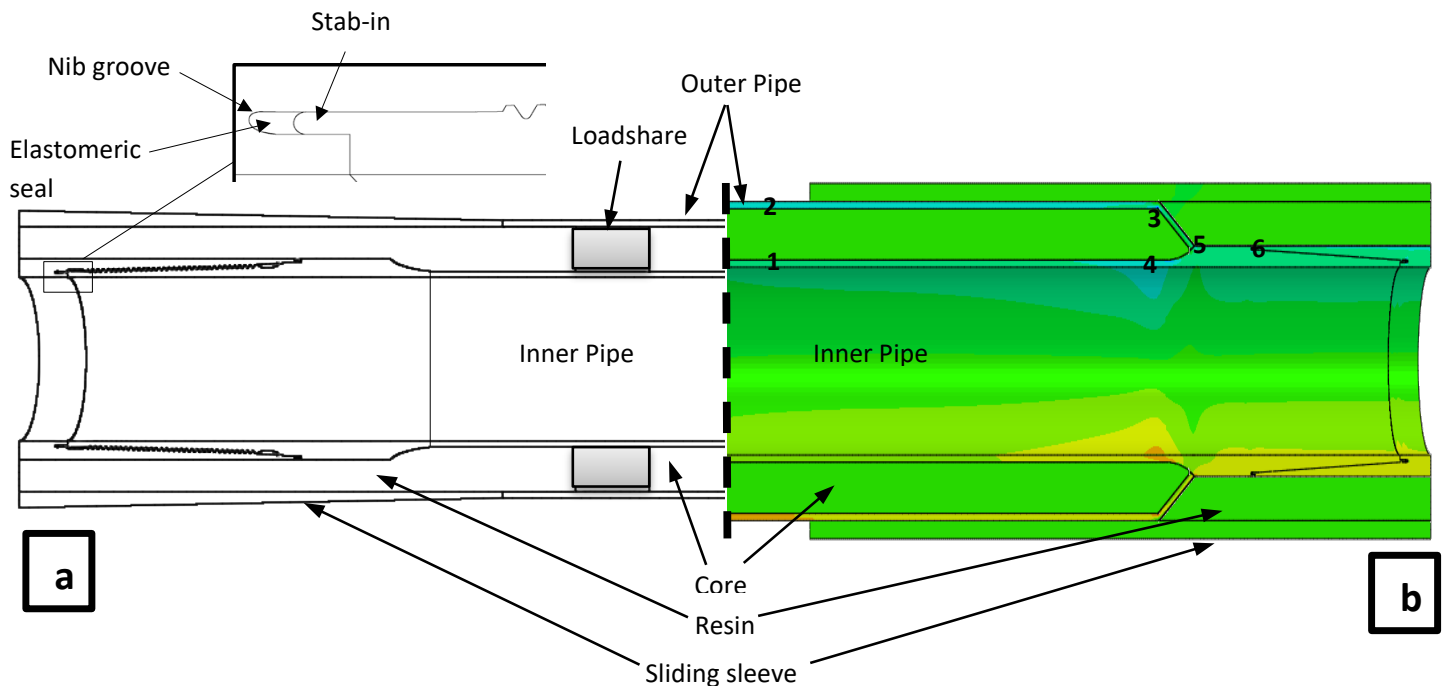

Figure 4 Snap-fit Connector in Sandwich Pipes: (a) Loadshare concept (b) Swaged weld concept

Although elastomeric seals could pose some issues when it comes to the reliability of stabbing screwed connectors, such as, the slip off and circumferential misalignment, they could offer some benefits when used in snap-fit connectors. In view of the stab-in method for snap connectors, the magnitude of compressive pre-stress in the elastomeric seal can be achieved by knowing the seal's material properties and strain energy calculations. Four different geometrical configurations were adopted for the snap-in region as can be seen in Figure 5 . The stab-in was designed to be $7 \mathrm{~mm}$ long and $2 \mathrm{~mm}$ thick with a variable radius nib groove utilised. All four models were subjected to axial loading and incorporated an elastomeric seal. Mechanical properties of ASTM A678B with elastic modulus of $202 \mathrm{GPa}$ and Poisson ratio of 0.29 were used for the line pipe in all analyses carried out in this study. In addition, the same material properties were assumed for both the pipes and the connectors. The results suggest that flattening the stab-in head (Figure5b) would create a better distribution of the peak stresses around that region. Creating an elliptical groove between the stabin length and the box with intention of relieving the stress concentration at the stab-in head was implemented as seen in Figure $5 \mathrm{c}$ while a fillet was introduced at the transition edge in Figure $5 \mathrm{~d}$. Although this significantly reduced the stress concentration at the stab-in head, it creates a new stress concentration spot at the point where the two surfaces get back in contact. 


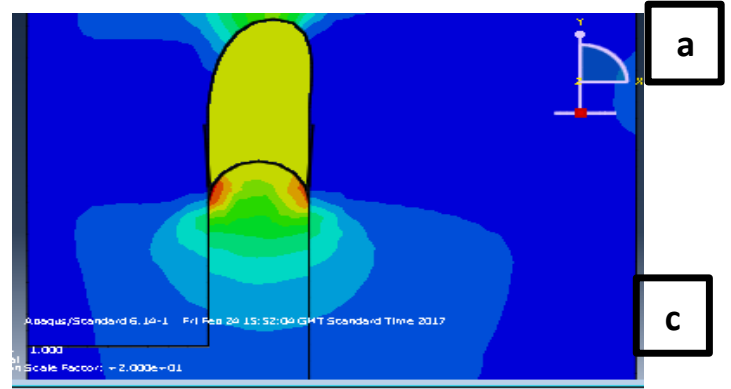

(a)

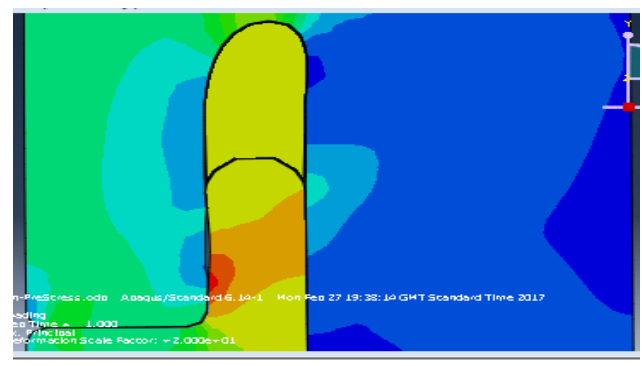

(c)

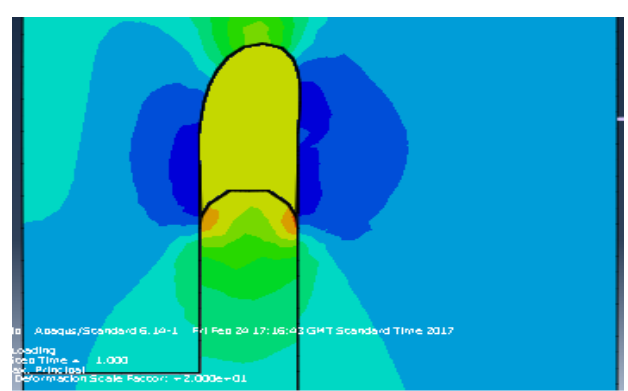

(b)

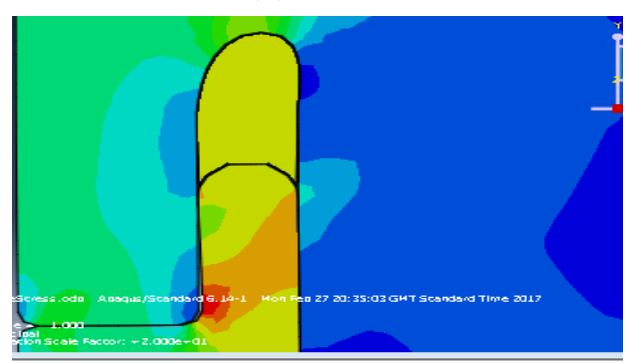

(d)

Figure 5 Maximum principal stress (red contour) for different nib groove modifications: (a) circular finish (b) chamfered finish (c) elliptical groove at stab-in (d) fillet at transition edge

The influence of the compressive pre-stress in the elastomeric seal was studied under external pressure and bending loads and a linear relationship was observed between the magnitude of prestress and the peak stress at the nib groove as seen in Figure 6b. Hydrostatic pressure equivalent to $1000 \mathrm{~m}$ water depth and a simplified yield curvature, $k_{y}$, defined below as

$$
k_{y}=\frac{2 \sigma_{y}}{E \cdot D}
$$

where $\sigma_{y}, E, D$ are the yield strength, elastic modulus and outer diameter of the outer pipe, respectively, were applied to all models in two separate analysis steps. The external pressure was applied first followed by the bending load. The mesh for the steel parts was generated using 3D solid elements C3D20R (20-node quadratic brick with reduced integration) which model bending dominated problems effectively and prevents the issue of shear locking which is usually associated with full integration elements undergoing bending deformation. With assumption of volumetric incompressibility, the mesh for the core polymeric layer was generated using C3D2OH elements to solve independently the pressure stress as a basic solution variable before coupling to the displacement solution to avoid singular behaviour arising from using overly sensitive displacement based solution to capture deformation in the annular material. The pre-stress applied $\left(\sigma_{p s}\right)$ and peak stress $\left(\sigma_{s p}\right)$ about the seal were normalised by the yield stress $\left(\sigma_{y}\right)$ of the joint material. It was also 
observed that the ductility and stiffness of the sealer affects the peak stresses at the nib groove with lower values of peak stress for higher sealer stiffness. The effect of the magnitude of pre-stress at the nib groove is independent of the sealer stiffness $E_{S}$ in that for all sampled $E_{S}$ the same trend can be seen. The pre-stressed seal acts as a form of dampener to the stress concentration that would normally spike at the nib groove and also helps in creating a more uniform stress distribution at the nib groove.
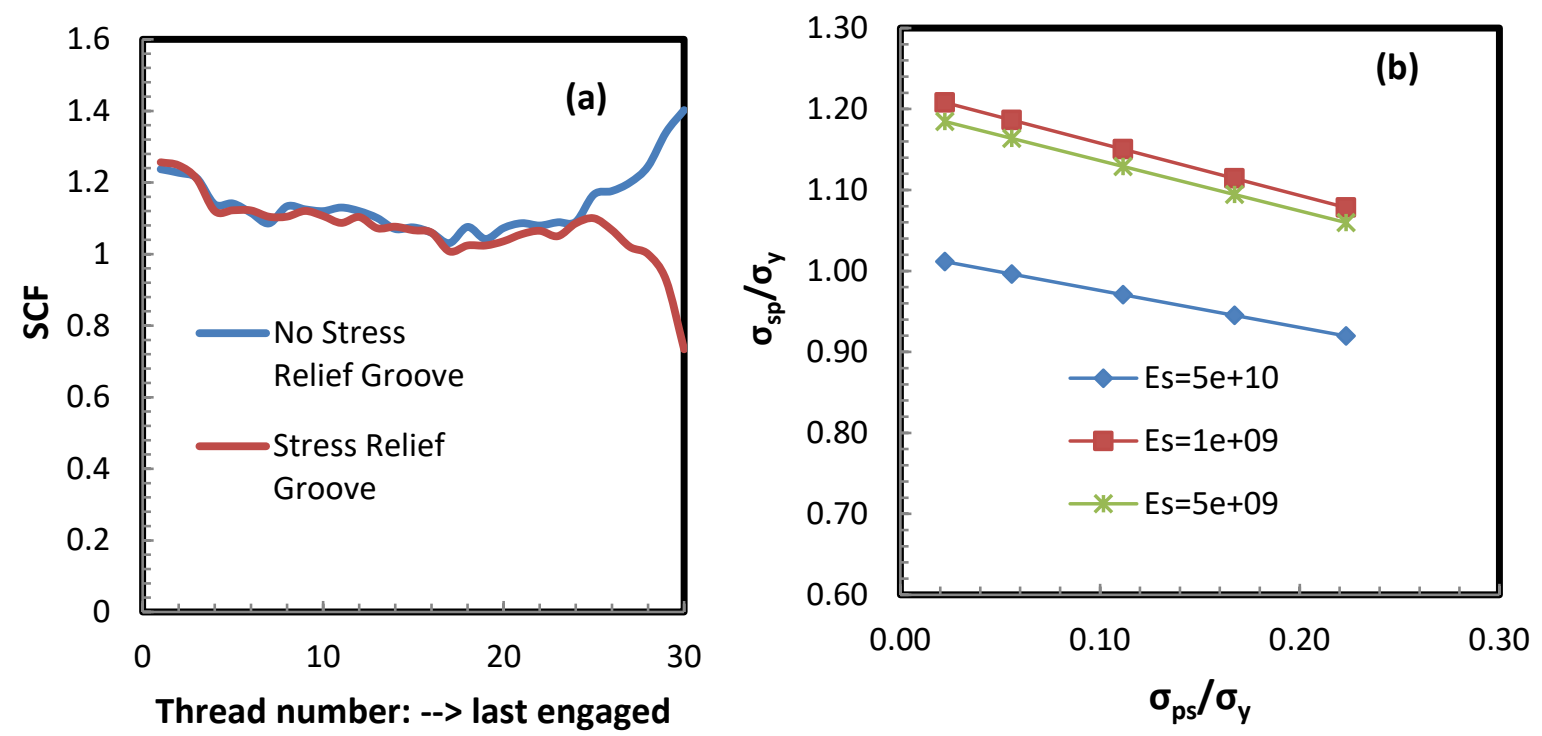

Figure 6 (a) Influence of SRG on SCF (b) Effect of compressive pre-stress and sealer modulus on peak stress at nib groove

\section{Comparative Studies of Pipe-in-Pipe vs Sandwich Pipe}

The performance of the proposed concept was compared for sandwich pipes (SP) and a conventional pipe-in-pipe (PiP) system. The dimensions and material properties of the pipes as listed in Table 1 were made consistent with that recorded by (Castello and Estefen, 2008) to meet standards for a maximum $\mathrm{U}$ value of $3 \mathrm{~W} / \mathrm{m}^{2}{ }^{\circ} \mathrm{C}$ and a water depth of $2500 \mathrm{~m}$. High density polyimide and polyurethane foam are used respectively in the core of the sandwich pipe and pipe-in-pipe. A SRG was adopted for both models as the advantages are shown to reduce the SCF at the last engaged thread of the pin (the last thread on the pin engaged with the box or the box engaged with the pin) as seen in Figure $6 a$.

Table 1 Geometric and material properties of SP and PiP

\begin{tabular}{|l|l|l|l|l|l|l|l|}
\hline & $D_{(i)}, \mathrm{mm}$ & $t_{(i)}, \mathrm{mm}$ & $D_{(o)}, \mathrm{mm}$ & $t_{(o)}, \mathrm{mm}$ & $t_{(c)}, \mathrm{mm}$ & $E_{(c)}, \mathrm{GPa}$ & $v_{(c)}$ \\
\hline $\mathrm{SP}$ & 168.83 & 6.35 & 273.05 & 6.35 & 45.97 & 0.521 & 0.42 \\
\hline $\mathrm{PiP}$ & 168.83 & 6.35 & 219.07 & 12.7 & 12.64 & 0.054 & 0.45 \\
\hline
\end{tabular}


The models were first axially loaded through the outer pipe alone (as is during J-lay installation) and then subjected to sagbend curvature (calculated using the outer pipe). The tension applied was rated to the required top tension required to install the pipeline as described in Bai and Bai (2005a). For these configurations: $1790 \mathrm{kN}$ for the PiP and $1049 \mathrm{kN}$ for the SP. The axial stress in both the PiP and SP were below $60 \%$ of the axial capacity of the outer pipe as recommended in. The top tension requirement for the sandwich pipe was calculated to be $60 \%$ of the required top tension for the PiP. The sagbend curvature $\left(0.00524 \mathrm{~m}^{-1}\right)$ was defined using a rotational displacement applied to a reference node linked to the outer pipe ends using a kinematic coupling in Abaqus. Initial ovality was assumed to be $0.5 \%$. Perfect bonding is assumed between the pipe layers using a kinematic tie constraint in Abaqus. A swage angle of $20^{\circ}$ was assigned to both models. The elastic SCF experienced in the field joint is shown in Table 2; a lower SCF indicates better performance from adopting this joint configuration for the pipe type. The regions of interest are as marked in Figure $4 b$; the pipe stresses were extracted from the models at region 2 . It should be mentioned here that the stress in the bare outer pipe used for the SCF calculation is simply calculated by adding both the axial stress from the top tension and bending stress from the sagbend curvature.

Table 2 SCF at regions of interest

\begin{tabular}{|l|c|c|c|c|}
\hline \multirow{2}{*}{ Region of interest (Figure 4b) } & \multicolumn{4}{|c|}{ SCF } \\
\cline { 2 - 5 } & \multicolumn{2}{|c|}{ Sandwich Pipe } & \multicolumn{2}{c|}{ Conventional Pipe-in-Pipe } \\
\cline { 2 - 5 } & Tension & Bending & Tension & Bending \\
\hline 3 (swaged outer pipe) & 3.05 & 2.27 & 2.63 & 2.20 \\
\hline 4 (inner pipe-connector ends) & 0.29 & 0.50 & 0.29 & 0.27 \\
\hline 5 (swaged weld) & 1.09 & 1.10 & 1.44 & 1.37 \\
\hline 6 (nib groove) & 0.37 & 0.48 & 0.64 & 0.72 \\
\hline
\end{tabular}

At the swaged weld region (region 5), the influence of having a weight bearing core can be clearly seen when the pipes are loaded in tension. Due to a higher wall thickness in the outer pipe of the PiP and the large difference in interlayer stiffness at the outer pipe-PUF contact boundary, the bulk of the tension is transferred directly to the connector through the swaged weld. This is not exactly the case in the SP, which having a load bearing core is able to transfer some axial loads to the inner pipe via the contact surface as is seen in Figure 7a where the axial stress acting along the inner pipe for both models is plotted. This core effect can be further seen as the PiP outperforms the SP at region 4 as the connector gets to the apex of the sagbend curvature. A load-bearing core translates to the inner pipe being a more active component in the mechanical behaviour of the connector assembly. 
This effect can also be seen in the results as the SP outperforms the PiP at region 5 under axial loading. The stress divergence at the connector weld for PiP and SP further signifies the influence of a load bearing core. As expected for the SP, the axial stress reduces as we move away from the connector and then begins to increase at a length that marks the point at which the load transfer from the core is significant. Because perfect bonding and elastic modelling is assumed in this work the stress distribution for the two models are similar. The difference in axial stress is principally a function of the stiffness of the core and the stress reduction at the pipe end is as a result of the applied boundary conditions.

On applying bending load, both the PiP and SP show a reduced SCF for the additional bending stress experienced in the outer pipe at region 3 , signifying that the snap-fit connector and the filler resin contribute more to the load bearing capacity of the joint in bending. The reduction in SCF for the SP is more significant owing to the influence of the load bearing core and we can infer that the SP will be more advantageous for an installation method with lower radius of curvature e.g. reel lay. The transferred moment from the outer pipe to the inner pipe is a function of both the stiffness of the core and the thickness of the snap-fit connector. Although utilising a load bearing core improves the bending capacity of the SP (Arjomandi and Taheri, 2012), the wall thickness has a significant effect on the stress concentration experienced at region 3 as a result of the change in geometry at the outer pipe swage. Figure7b shows a gradual stress increase in the inner pipe for both models as we move away from the connector. This is because the snap-fit connector stiffness (due to its thickness) is large enough to impose a rotational constraint at the connector weld. This means that a significant moment transfer will have to occur via the core. This explains the stress peak at the mid-length; which signifies the creation of a second curvature apex in the inner pipe. The stress divergence between the SP and PiP at the connector weld is similar to that experienced under tension. . From the results, it can be deduced that the advantage derived from the core as a load transfer option could be significantly affected depending on the magnitude of the applied load and loading history. It can also be seen from Fig $7 \mathrm{~b}$ that the sleeve and filler resin play a more significant role in maintaining the continuity of bending stiffness across the field joint, reflected by the gradual incline of the stress between the connector weld and mid-length. 

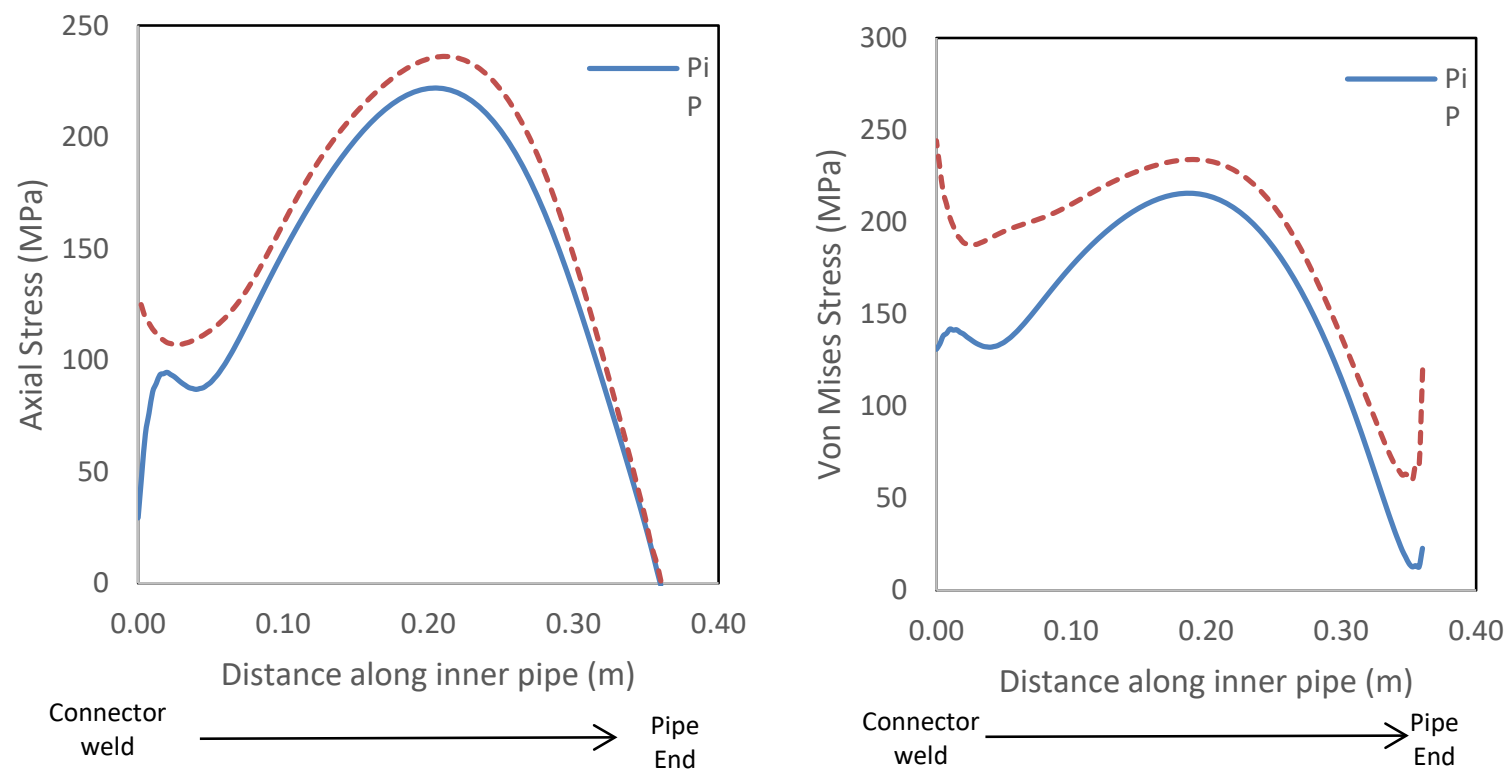

Figure 7 Stress along inner pipe (left) Axial loading (right) Bending (after axial loading)

At region 4, it can be seen that the PiP outperforms the SP when the sagbend curvature is applied. This is expected as the load transfer between the interlayer boundaries in the SP is more significant than that in the PiP, so the inner pipe would carry more loads in the SP while in the PiP a bulk of the load is transferred through the swaged weld. This is in addition to the stress concentration that would naturally be imposed on region 4 due to the difference in stiffness between the inner pipe and the connector. The same reasons as explained for the performance of the pipes in region 4 can be expressed by results for region 5. Since the bulk of the load in the PiP is transferred via the swaged weld, it is no surprise the SP outperforms it for both load cases at region 5. Results for region 6 reveals that the condition of the swaged weld for this joint concept has a significant directly proportional relationship to the stress concentration experienced at the nib groove. The SCF at region 6 can be seen to increase when the connector goes through the sagbend mainly because of the nib groove is located at the apex of the curvature. The low SCF at the nib groove indicates that good load transference occurs between the box and pin of the snap-fit connector. This is due to the perfect bond condition assumed for the models. This condition is however not realistically attainable. It should be mentioned here that the SCF at the nib groove is significantly attributed to geometric influence. 
An important requirement for deepwater pipelines is the thermal performance. It plays a significant role in determining what flow assurance strategies are to be adopted. Having an unfilled annular space between the core and the inner surface of the external pipe or outer surface of the internal pipe would indeed improve thermal performance as compared to having perfect adhesion but as shown in study by (Arjomandi and Taheri, 2011), (Arjomandi and Taheri, 2012), (He et al., 2015) a fully bonded sandwich pipe presents the most structurally efficient option under external pressure and bending loads. The influence of the interlayer adhesion conditions on the SCF experienced in our regions of interest was studied as shown in Figure 8a. The interaction was defined with the steel pipes being the master surface and the core being the slave surface. Surface to surface contact discretization method was used and the where applicable rotational degree of freedoms were tied. Abaqus default contact controls were used. The models considered four different sets of interlayer adhesion conditions namely:

- Fully bonded (FB) condition: The core was bonded to both internal and external pipes using the kinematic tie constraint formulation.

- Inner pipe unbound (IUB): A frictionless contact interaction property was used to define the contact conditions between the core and inner pipe. The core-outer pipe contact condition remained as in FB.

- Outer pipe unbound (OUB): A frictionless contact interaction property was used to define the contact conditions between the core and outer pipe. The core-inner pipe contact condition remained as in FB.

- All unbound (AUB): A frictionless contact interaction property was used to define the contact conditions between the core and both pipes.

From the results, it can be seen that the FB model relatively produces the best performance joint of all options considered especially at the inner pipe-connector weld region and nib groove. The AUB model produces the least performance joint for obvious reason linking to poor load transfer between the concentric regions of the sandwich pipe making it difficult for the pipe to carry loads as a compact unit. The results did not seem sensitive to whether the inner pipe or outer pipe was unbounded from the core as long as one was bound as seen from OUB and IUB results, although from Figure $8 \mathrm{~b}$ it can be inferred that the elastic modulus of the core has an effect on this conclusion. We can see that ensuring the outer pipe remains bound to the core would be more beneficial than bounding the inner pipe for regions 3, 4, 6 while the inner pipe being bound preferentially to the outer pipe gives a better performance only at region 5 when utilising a much stiffer $\left(E_{r} / E_{c}=0.1\right)$ core. To understand better, we need to clarify the load paths for the models. 
For the FB model, the inner pipe is generally loaded via the core and locally loaded through the connector-inner pipe weld. As the connector imposed stresses would be acting away from the weld and through the length of the inner pipe, good load transference from the outer pipe ends to the inner pipe via the core would help in reducing the stress concentration at region 4 . This also clarifies why having IUB is relatively more beneficial than OUB as the loads are applied explicitly to the outer pipe. Once again, we can see why having good adhesion is important to accruing optimal structural benefits from the sandwich pipe.
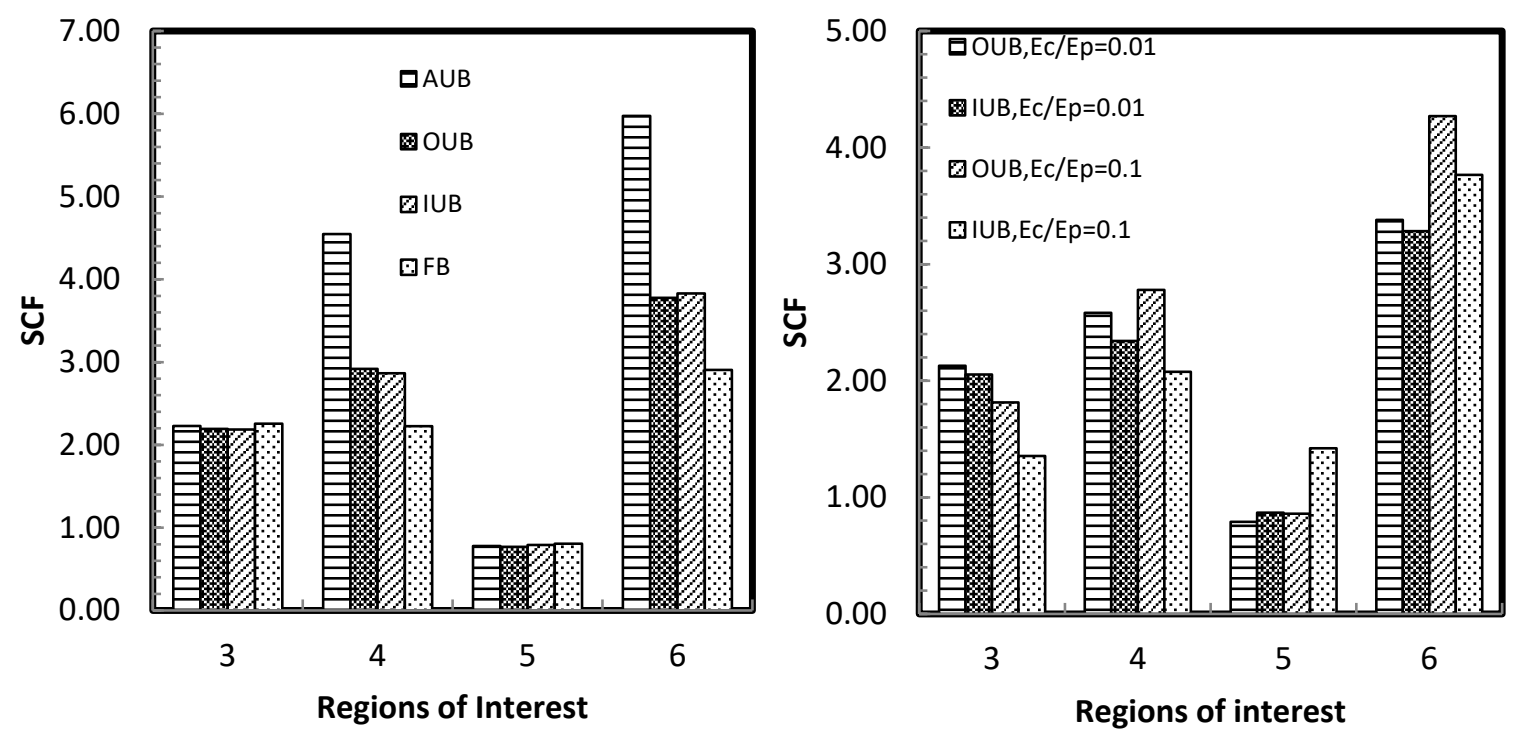

Figure 8 SCF at regions of interest (a) Influence of interlayer conditions (b) Influence of core modulus on IUB, OUB

The influence of the resin-to-core stiffness ratio on the peak stress experienced in the nib groove is shown in Figure 9. The peak stress is normalised by the yield strength of the connector material and reported as the peak stress ratio. The two extreme ratios $\left(E_{r} / E_{c}=0.001,1000\right)$ are not practical and only considered for trend purposes. As the stiffness ratio increases, the peak stress at the nib groove reduces for all resin stiffness values studied. This is simply due to the differential in bending stiffness between the sandwich pipe and the field joint region. It can be seen that for a fixed stiffness ratio, a stiffer resin will only lead to additional stress concentration at the nib groove, as there would exist a better transfer of the load to the connector whose stiffness was kept constant for this study. For example, at unity stiffness ratio, it can be seen that the higher the resin modulus, the higher the peak stress at the nib groove. This can be attributed to the decrease in the bending stiffness differential between the connector and the resin meaning that stress concentration spots in the connector will experience more loads because of the better load transference by the resin. The broken line illustrates the trend in the reduction of the peak stress around the nib groove as the resin stiffness increases relative to the core stiffness with a design trade-off which will have to 
consider the resin-to-core stiffness ratio and also the resin stiffness. With high resin stiffness and high stiffness ratio, the stress concentration would be expected at the joint between the inner pipe and the connector. Once the core (sandwich pipe) stiffness begins to increase, the stress concentration about the inner pipe joint to the connector starts to attenuate and the bending loads would be better transferred to the nib groove through the resin leading to the stress amplification.

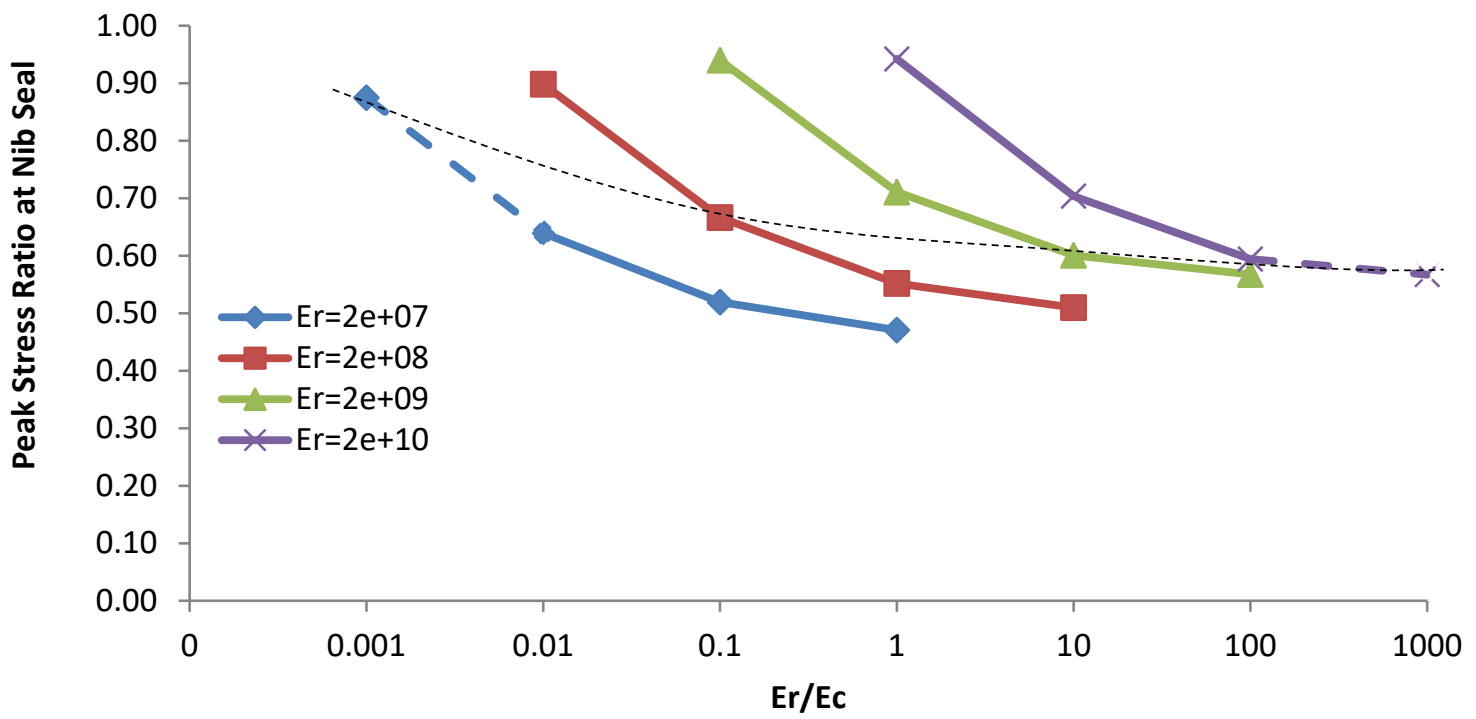

Figure 9 Influence of resin-core stiffness ratio on peak stress at nib groove 


\section{Conclusions and Further Work}

The investigation into performance enhancing geometric and mechanical modifications to snap-fit connectors for sandwich pipes has been carried out. Firstly, regions susceptible to high stress concentrations under a combination of loadings were identified. Thereafter, with the aid of FE modelling, we were able to highlight some trends that would lead to an improved performance for the snap-fit connector and the following conclusions were drawn:

- The modification of the nib groove to utilise a variable radii will improve the performance of the snap-fit connector for a sandwich pipe configuration.

- The use of an elastomeric sealer coupled with compressive pre-stress improves the stress distribution about the nib groove and as such reduces the stress concentration. A chamfer finish to the head of the stab-in also improves the stress distribution.

- The resin to core stiffness ratio influences the mechanical behaviour of the field joint. An optimum resin to core ratio would be key to attain the best performance from the snap-fit connector installed on sandwich pipes.

A comparative study examined the mechanical behaviour of the snap-fit connector concept in sandwich pipes and conventional pipe-in-pipes for a practical installation case. The results did not show a preferred configuration but revealed key regions of interest in which the SP outperformed the PiP and vice versa. The type of loading also weighed in on the comparative performance of the two pipes.

\section{Acknowledgements}

The authors would like to acknowledge the financial support of the University of Aberdeen, through the Elphinstone PhD studentship, and the support of the Maxwell computer cluster funded by the University of Aberdeen. 


\section{References}

ADEOSUN, M. 2016. Low oil prices taking toll on deepwater capex. Offshore Magazine. April 2016 ed. Tulsa, OK, USA: PennWell Corporation.

API-RP-1111 2015. Design, Construction, Operation and Maintenance of Offshore Hydrocarbon Pipelines (Limit State Design) 5th Edition. American Petroleum Institute: API Publishing Services.

ARJOMANDI, K. \& TAHERI, F. 2011. The influence of intra-layer adhesion configuration on the pressure capacity and optimized configuration of sandwich pipes. Ocean Engineering, 38, 1869-1882.

ARJOMANDI, K. \& TAHERI, F. 2012. Bending capacity of sandwich pipes. Ocean Engineering, 48, 1731.

BAI, Y. \& BAI, Q. 2005a. Installation Design. In: Y, B. \& Q, B. (eds.) Subsea Pipelines and Risers. Oxford: Elsevier Science Ltd.

BAI, Y. \& BAI, Q. 2005b. Subsea Pipelines and Risers / Installation Design-Chapter 34, Oxford, Elsevier Science Ltd.

CASTELLO, X. \& ESTEFEN, S. F. 2008. Sandwich Pipes for Ultra Deepwater Applications. Offshore Technology Conference.

CRAIG, M. \& DICK, M. 1995. SnapLay. Subtech '95: Addressing the Subsea Challenge. Aberdeen, UK: Society of Underwater Technology.

DASSAULT.SYSTÈMES 2014. Abaqus User's and Theory Manuals. Version 6.14.

ESTEFEN, S. F., LOURENÇO, M. I., FENG, J., PAZ, C. M. \& BESSA DE LIMA, J. D. 2016. Sandwich Pipe for Long Distance Pipelines: Flow Assurance and Costs. V005T04A025-C1 - Volume 5: Pipelines, Risers, and Subsea Systems.

ESTEFEN, S. F., NETTO, T. A. \& PASQUALINO, I. P. 2004. Strength Analyses of Sandwich Pipes for Ultra Deepwaters. 72, 599-608.

GEERTSEN, C., GROBBELAAR, W., JONES, P. \& MAHATVARAJ, A. 2017. Mechanically Connected High Thermal Efficiency Pipelines: Reducing SURF Costs by 30\%. Offshore Pipeline Technology Conference. Amsterdam: OPT.

GMC 2014. Intelligently Connected Pipe (Product Catalog). In: LTD, G. (ed.). Houston, TX, USA: GMC Ltd.

HE, T., DUAN, M., WANG, J., LV, S. S. \& AN, C. 2015. On the external pressure capacity of deepwater sandwich pipes with inter-layer adhesion conditions. Applied Ocean Research, 52, 115-124.

HSE-UK 2003. RR105: Review of the performance of high strength steels used offshore. Health and Safety Executive, UK. HSE. 
OSI 2013. Advanced Connection Systems For Offshore Tubulars (Catalog). In: OSI (ed.). Oil States Industries Inc.

POLLACK, J. \& RIGGS, D. C. 2011. Improved Concentric Thread Connectors for SCRs and Pipelines. Offshore Technology Conference. Houston, Texas, USA: Offshore Technology Conference. TAFRESHI, A. 1999. SIF evaluation and stress analysis of drillstring threaded joints. International Journal of Pressure Vessels and Piping, 76, 91-103.

TAYLOR, D., KELLY, A., TOSO, M. \& SUSMEL, L. 2011. The variable-radius notch: Two new methods for reducing stress concentration. Engineering Failure Analysis, 18, 1009-1017.

THETHI, R. \& WALTERS, D. 2003. Alternative Construction for High Pressure High Temperature Steel Catenary Risers. Offshore Pipeline Technology. USA: 2H Offshore Inc.

TRUE, W. R. 1996. Deepwater pipelay prospects prompt study of mechanical connectors. Oil \& Gas Journal, 94, 72.

VAN WitTEnBERGHE, J., DE BAETS, P., DE WAELE, W., GALLE, T., BUI, T. T. \& DE ROECK, G. 2011. Design characteristics that improve the fatigue life of threaded pipe connections. In: VAN WITTENBERGHE, J. (ed.). Ghent University, Laboratory Soete.

VERBECK, R. J. \& HOLLAND, M. J. 2010. Joining Pipelines Without Welding. Oil and Gas News, Bahrain Review, 3.

WALTERS, D. \& THETHI, R. 2002. A Step Change Application of Threaded and Coupled Connection. Offshore Pipeline Technology. USA: 2H Offshore Inc. 